\title{
RASTREADOR SOLAR E COMPARAÇÃO DE EFICIÊNCIA NA GERAÇÃO FOTOVOLTAICA
}

\section{ARTIGO ORIGINAL}

JÚNIOR, Antonio Carlos Lemos ${ }^{1}$

SILVA, Leandro Aureliano da ${ }^{2}$

SANTOS, Marcelo Soares dos ${ }^{3}$

SILVA, Michelle Pio Barbosa da ${ }^{4}$

JÚNIOR, Antonio Carlos Lemos. Et al. Rastreador solar e comparação de eficiência na geração fotovoltaica. Revista Científica Multidisciplinar Núcleo do Conhecimento. Ano 05, Ed. 08, Vol. 13, pp. 44-62. Agosto de 2020. ISSN: 2448-0959, Link de acesso: https://www.nucleodoconhecimento.com.br/engenharia-eletrica/rastreador$\underline{\text { solar }}$

\section{RESUMO}

Com o tema de eficiência energética e energias renováveis, o presente artigo trata do desenvolvimento de um protótipo de rastreador solar em eixo polar. A programação foi desenvolvida na plataforma IDE Arduino, utilizando resistores dependentes de luz (LDR) para realizar a localização do sol, permitindo que os dados fossem tratados

\footnotetext{
${ }^{1}$ Mestre em inovação tecnológica pela Universidade Federal do Triângulo Mineiro UFTM, Especialista em Processamento na Indústria Sucroalcooleira pelas Faculdades Associadas de Uberaba - FAZU e Engenheiro Eletricista pela Universidade de Uberaba - UNIUBE.

2 Doutorado em processamento da informação pela Universidade Federal de Uberlândia - UFU e Mestre pela Escola de Engenharia de São Carlos - USP.

${ }^{3}$ Graduado em Engenharia Elétrica.

${ }^{4}$ Graduado em Engenharia Elétrica.
} 
pelo microcontrolador do Arduino que por sua vez aciona o micro motor para corrigir a posição do painel fotovoltaico. Foi realizada a comparação de geração de energia elétrica entre o sistema com o protótipo do rastreador solar e um painel fotovoltaico fixo. Para realizar as medições de geração utilizou-se sensores de tensão e corrente. Todos os dados foram gravados em um SD Card e posteriormente realizadas as análises dos dados coletados. O painel fotovoltaico com rastreador solar mostrou um aumento na potência do sistema. Foi comprovado o funcionamento do rastreador solar e o aumento da eficiência do painel fotovoltaico.

Palavras-chave: Eficiência energética, energias renováveis, rastreador solar, sistema fotovoltaico, microcontrolador.

\section{INTRODUÇÃO}

Com o aumento populacional e desenvolvimento industrial em escala global ocorre em consequência a crescente demanda por energia elétrica. Estamos vivendo um momento em que há uma missão de geração de energia por meio de fontes renováveis, devido ao grande impacto ambiental causado pelas fontes de geração proveniente dos combustíveis fósseis, e à insustentabilidade de como os obtemos. Existem grandes iniciativas e métodos aplicados de formas alternativas de geração de energia. No Brasil, temos um grande potencial de geração a partir da radiação solar, potencial eólico, marés, entre outros. No que se aplica à geração fotovoltaica, há grandes estudos para aumentar a eficiência dos sistemas.

Um exemplo de geração fotovoltaica é a Alemanha que em sua melhor área de radiação solar tem uma capacidade inferior à pior área do Brasil. O território brasileiro possui um potencial de geração fotovoltaica imenso, porém que ainda está necessitando de melhoras no setor (CABRAL; TORRES; SENNA, 2013).

A grande barreira no desenvolvimento dos sistemas fotovoltaicos é a eficiência dos módulos, percentual de energia solar transformada em energia elétrica, que ainda é muito baixa. Painéis comercializados atualmente, geralmente policristalino, tem sua 
eficiência entre $15 \%$ e $19 \%$, sendo os painéis com mais de $17 \%$ considerados de alto rendimento (PORTAL SOLAR, 2019).

Basicamente a radiação solar, após atravessar a atmosfera, é dividida em três componentes principais: a radiação direta que é a radiação que atinge diretamente a superfície, a radiação difusa que é aquela que alcança a superfície terrestre a partir de todas as direções pelos componentes da atmosfera e a radiação refletida, também chamada albedo, que é aquela que é refletida da superfície e depende das propriedades ópticas da superfície. A soma destas três componentes é a energia total incidente no painel solar (MAGARREIRO; FREITAS; BRITO, 2016). As três componentes de radiação solar são apresentadas na Figura 1.

Figura 1 - Radiação direta, difusa e refletida.

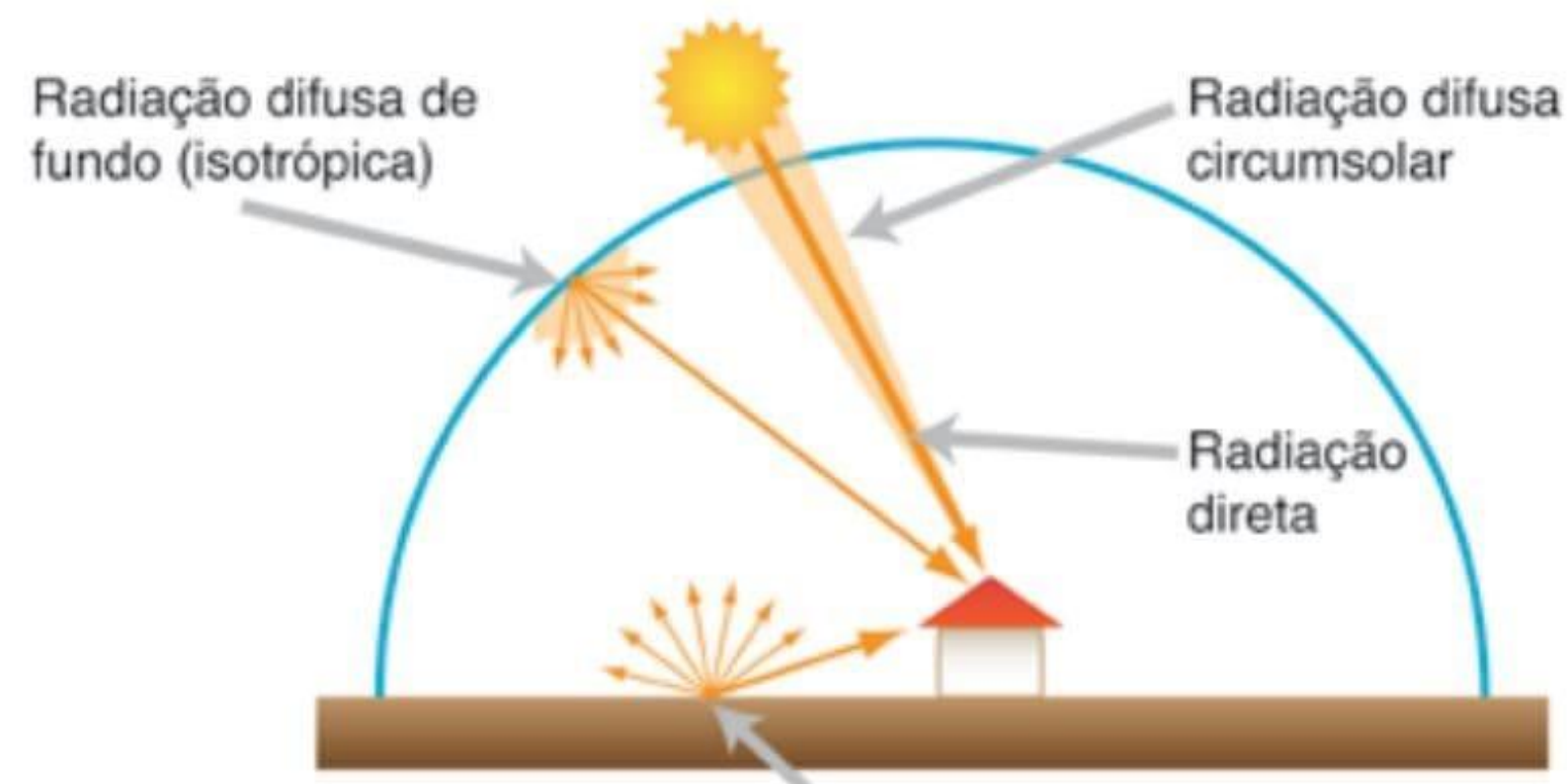

\section{Radiação refletida \\ pelo solo (especular)}

Fonte: MAGARREIRO; FREITAS; BRITO, 2016.

A inclinação dos painéis varia de acordo com a latitude da localização da instalação. Considera-se também que pequenas variações no grau de inclinação não interferem em níveis significativos na geração do sistema (PINHO; GALDINO, 2014). 
Há disponível livros e portais na internet com pesquisas de quase duas décadas contendo levantamentos de irradiação solar diária média, onde é possível definir o local que se quer ter informações e através das coordenadas é demonstrado o potencial fotovoltaico. O banco de dados disponível no SunData contém informações de mais de 72 mil pontos em todo território brasileiro (CRESESB, 2018).

Para aumentar a eficiência com o que se tem já desenvolvido, foi proposta a tecnologia de rastreador solar em um eixo polar, que consiste em rastrear o posicionamento do sol e direcionar o painel fotovoltaico de modo que ele fique sempre perpendicular em relação ao sol.

Para constatar se houve o aumento da eficiência, foi realizada a comparação entre um sistema convencional (painel fixo) e um sistema com o rastreador solar (painel móvel).

\section{MATERIAIS E MÉTODOS}

A proposta do projeto é melhorar o aproveitamento dos módulos fotovoltaicos, sendo montado dois sistemas com módulos idênticos, um sistema com rastreados solar e outro sistema fixo. Após a coleta dos dados, realizou-se uma análise para comparar os dois sistemas e apresentar o mais eficiente.

Foram utilizados dois módulos fotovoltaicos de silício policristalino da marca AKTHON conforme Figura 2, com potência máxima de $25 \mathrm{~W}$, tensão nominal $17,2 \mathrm{~V}$ e tensão de circuito aberto de $21,5 \mathrm{~V}$, com corrente nominal de $1,45 \mathrm{~A}$ e a corrente em curto circuito $1,56 \mathrm{~A}$. 
Figura 2 - Módulo fotovoltaico.

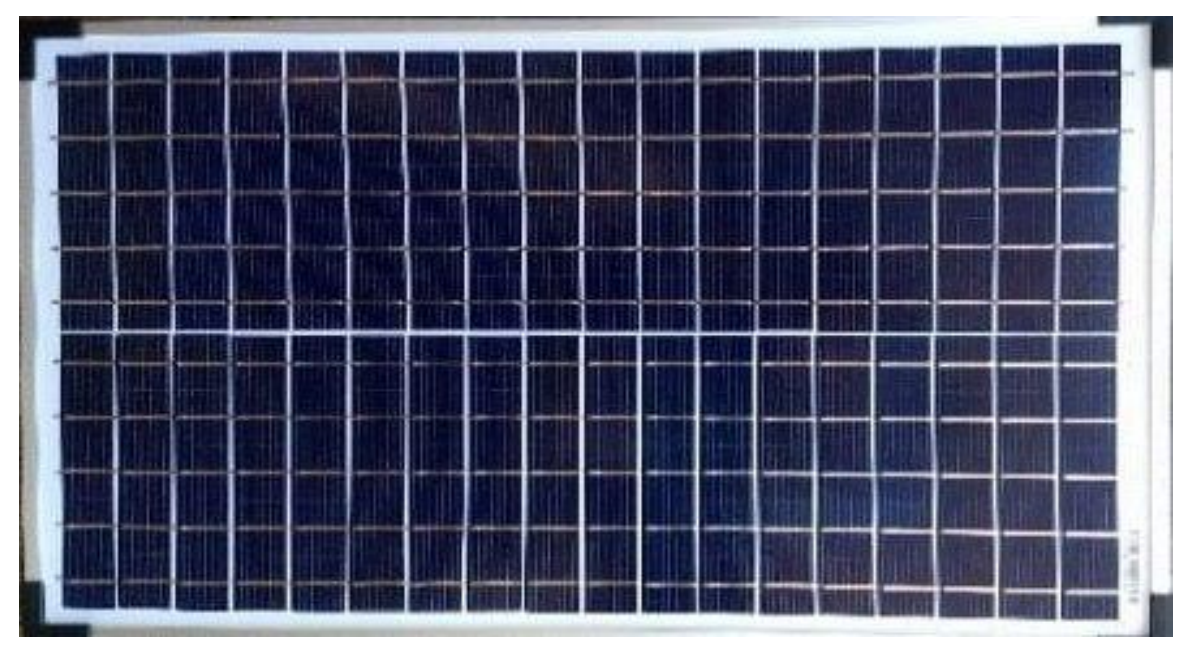

Fonte: Os autores, 2019.

A Figura 3, mostra o Arduino que pode ser programado para processar entradas e saídas entre o dispositivo e os componentes que estejam conectados a ele externamente. Sua tensão de operação é de $5 \mathrm{~V}$ a 12V. Possui 54 portas digitas (15 podem ser usadas como PWM) e 16 analógicas, com microcontrolador ATmega2560, memória flash 256kB, SRAM 8kB, EEPROM 4kB e velocidade do clock de $12 \mathrm{MHz}$. (ATMEL, 2014).

Figura 3 - Arduino ATMEGA 2560.

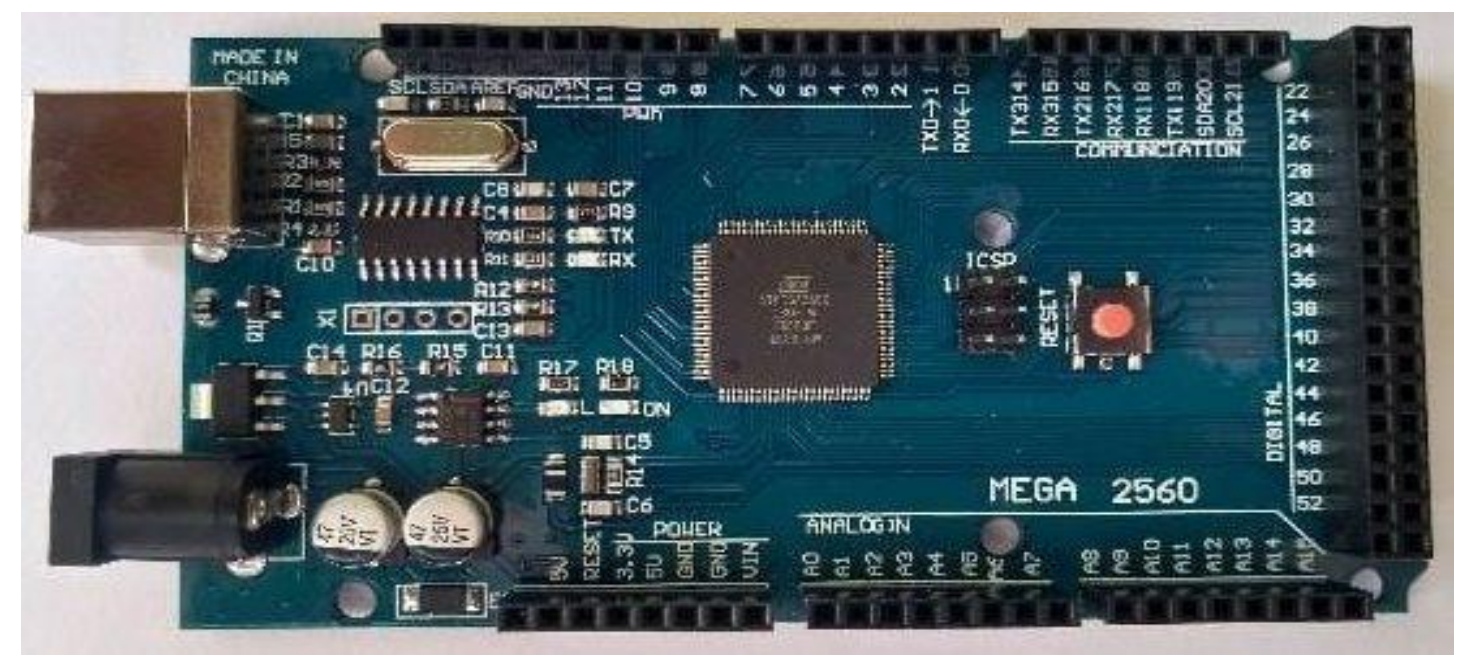

Fonte: Os autores, 2019. 
No projeto o Arduino Mega 2560 foi utilizado para ser o dispositivo principal de processamento. Ele faz a leitura, processamento e armazenamento dos dados de tensão, corrente, data, hora, faz a leitura dos sensores de luminosidade LDR, compara e executa o controle da ponte H L298n para girar o motor e grava os dados no cartão SD. O algoritmo desenvolvido é então gravado no Arduino Mega 2560 que irá executálo realizando os cálculos das rotinas programadas.

O módulo sensor de tensão Figura 4 foi utilizado para realizar as medições de tensão de geração dos sistemas. Tensão de trabalho de 0,02 - 25 VDC. Foi instalado em paralelo com a placa fotovoltaica e a medição é a de tensão de circuito aberto (VOC).

Figura 4 - Sensor de tensão.

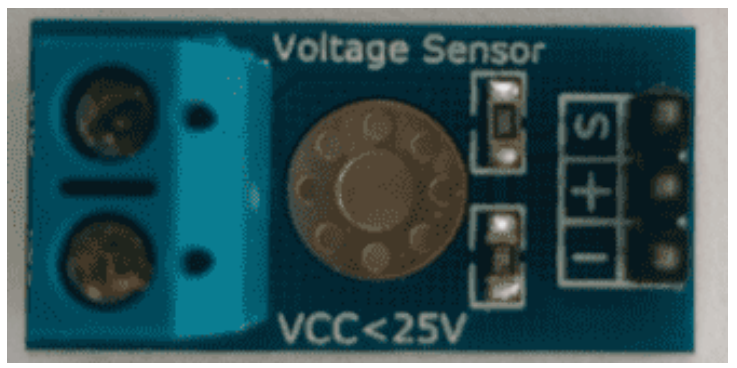

Fonte: Os autores, 2019.

O Sensor de corrente escolhido foi o ACS712 segundo Figura 5, que tem a leitura de corrente contínua. Foi instalado em série com a placa fotovoltaica e a medição feita é a de corrente de curto circuito (ISC).

Figura 5 - Sensor de corrente.

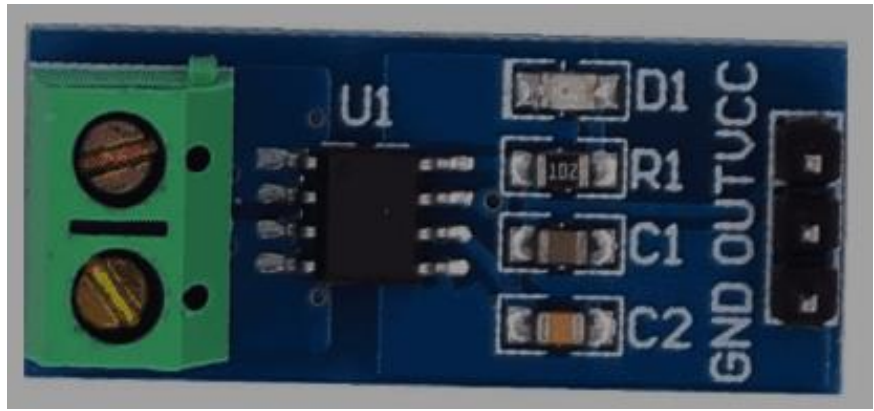

Fonte: Os autores, 2019. 
O RTC (Real Time Clock) DS3231 demonstrado na Figura 6, é um relógio de tempo real. Ele foi utilizado para fornecer informações como segundo, minutos, dia, data, mês e ano. Foi essencial para ter a informação do momento de cada leitura.

Figura 6 - Módulo RTC.

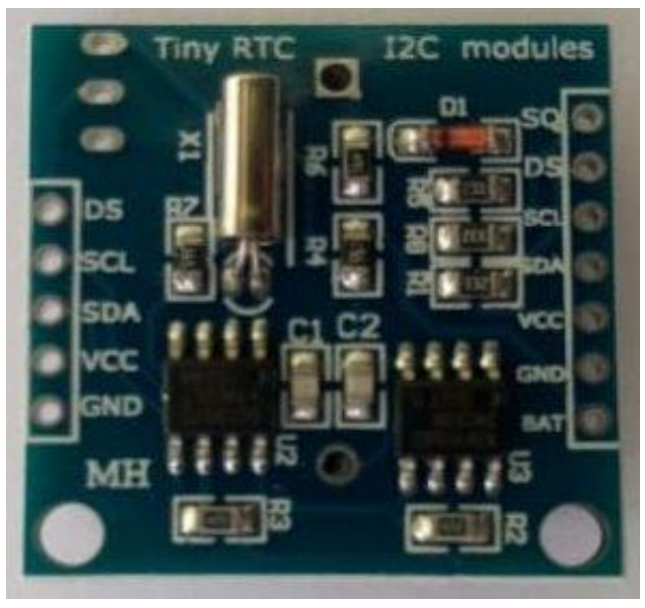

Fonte: Os autores, 2019.

O módulo para leitura e escrita em cartão SD conforme Figura 7, foi utilizado para a criação do datalogger, que tem a função de coletar e armazenar os dados de outros instrumentos, através de um sistema de contagem de pulsos eletrônicos, emitidos pelo instrumento. Com este módulo foram gravadas no cartão SD as informações de corrente, tensão das placas fotovoltaicas e informações de data e hora.

Figura 7 - Módulo leitor de cartão Sd Card.

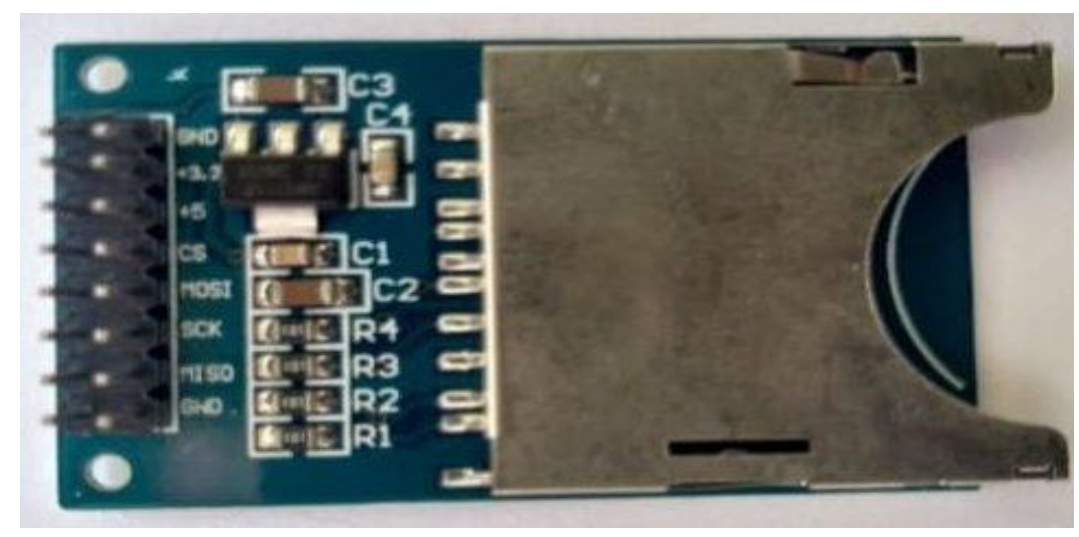

Fonte: Os autores, 2019. 
A Ponte H L298N demonstrada na Figura 8, foi utilizada para obter-se a inversão de lado de rotação do motor, para controlar o giro do módulo fotovoltaico tanto no sentido horário como no anti-horário.

Figura 8 - Ponte H L298N.

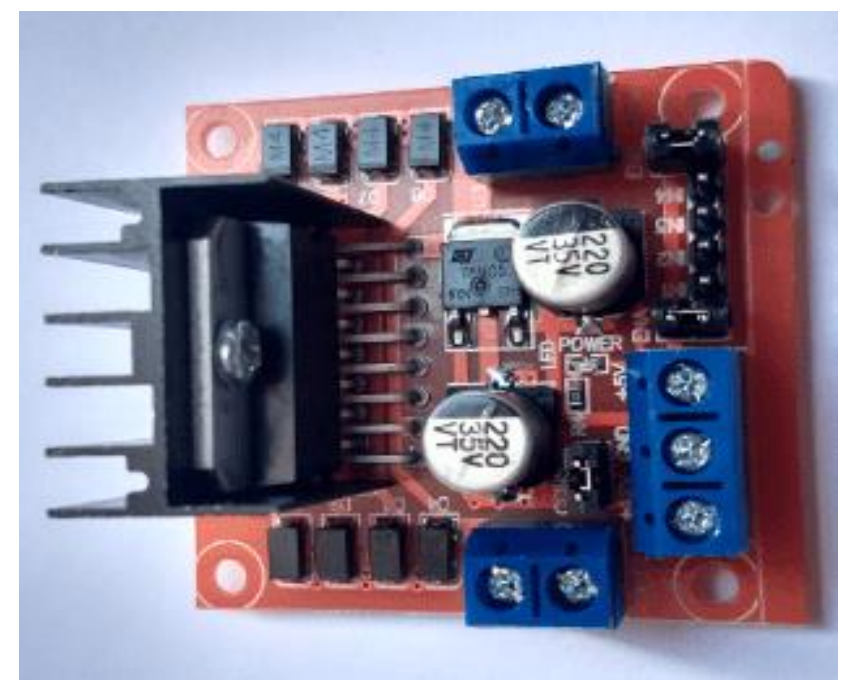

Fonte: Os autores, 2019.

Para efetuar os movimentos do eixo, o Arduino envia um sinal elétrico para a ponte $\mathrm{H}$ que por sua vez controla o giro do motor. O motor escolhido tem o bloqueio no eixo, o que impossibilita um giro involuntário do sistema, conforme a Figura 9.

Figura 9 - Micromotor com redutor.

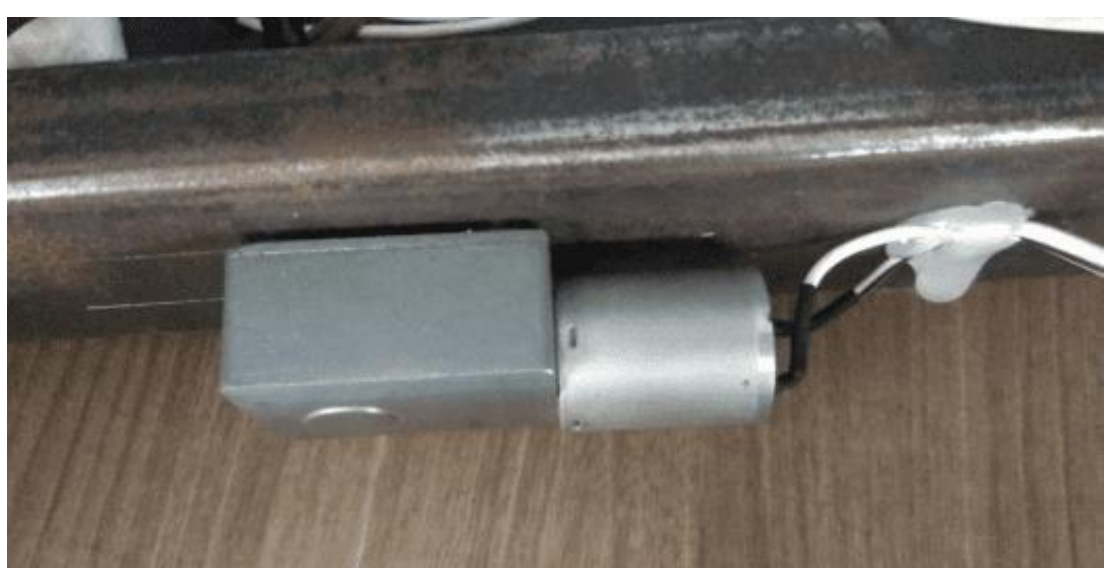

Fonte: Os autores, 2019 
O Display LCD foi utilizado para exibir várias informações e dados como: tensão e corrente das placas fotovoltaicas, data e hora, demonstrado na Figura10.

Figura 10 - Display LCD.

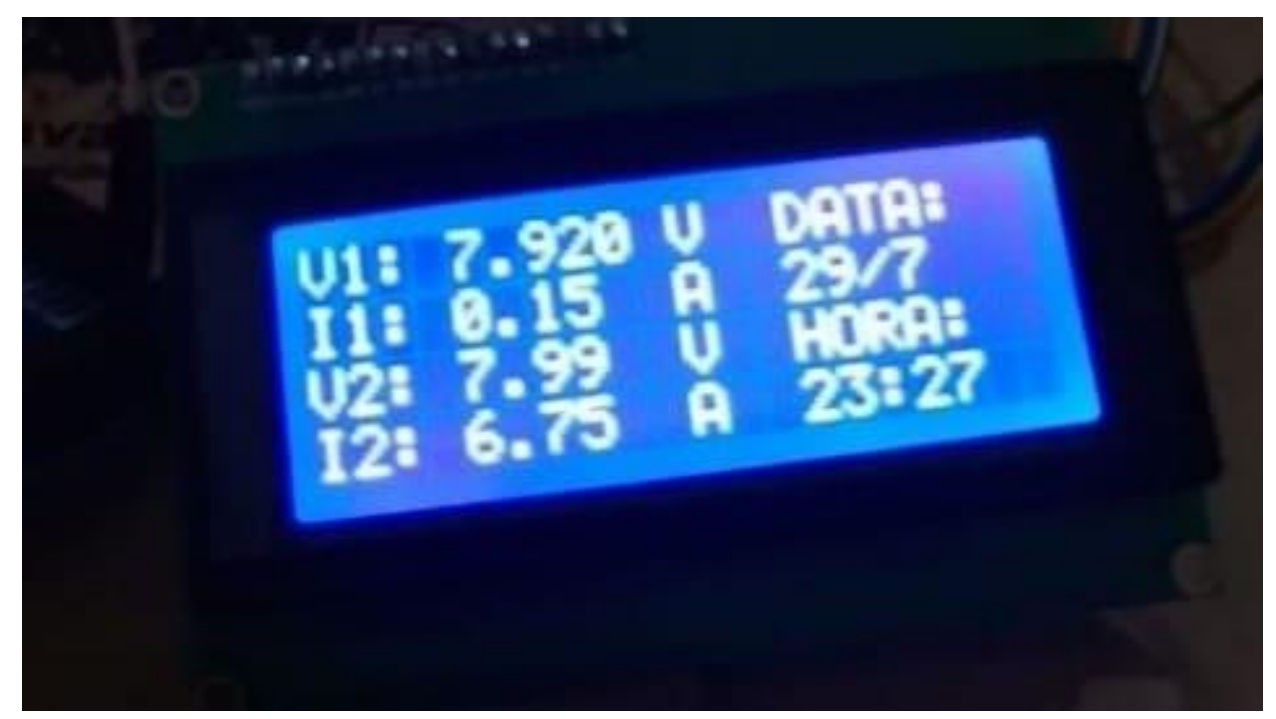

Fonte: Os autores, 2019.

A Figura 11 mostra as conexões de todo o projeto, que foram feitas através dos pontos da placa protoboard, um método mais fácil e rápido para testes e alterações no processo de montagem.

Figura 11 - Placa Protoboard.

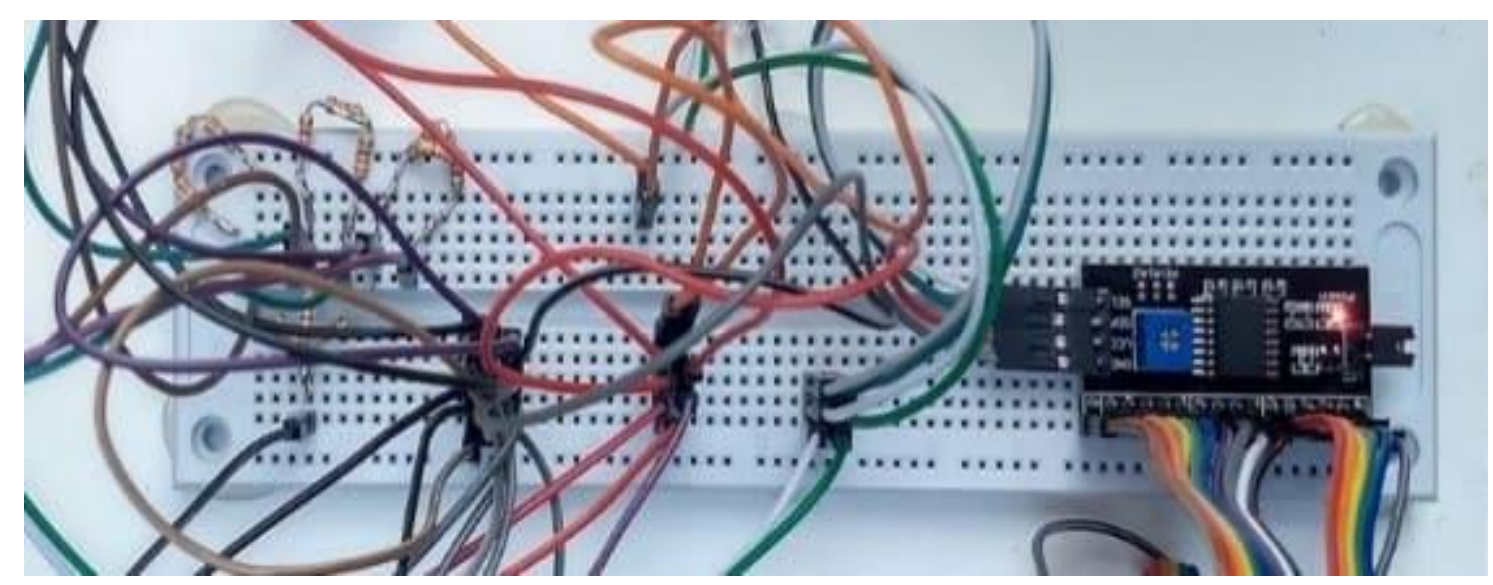

Fonte: Os autores, 2019. 
Os Sensores de Luminosidade LDR (Light Dependent Resistor) demonstrado na Figura12, foram instalados acima da placa e são responsáveis por fazer a leitura da iluminação e enviar esse valor para ser tratado pelo programa desenvolvido para o Arduino. Após a comparação dos valores dos dois LDR's, transmitiram-se sinais para que o motor possa ser acionado e girar a placa no sentido do LDR com menor valor de iluminação. Esse processo foi repetido durante todo o dia, para que o posicionamento da placa fotovoltaica fosse corrigido.

Figura 12 - LDR.

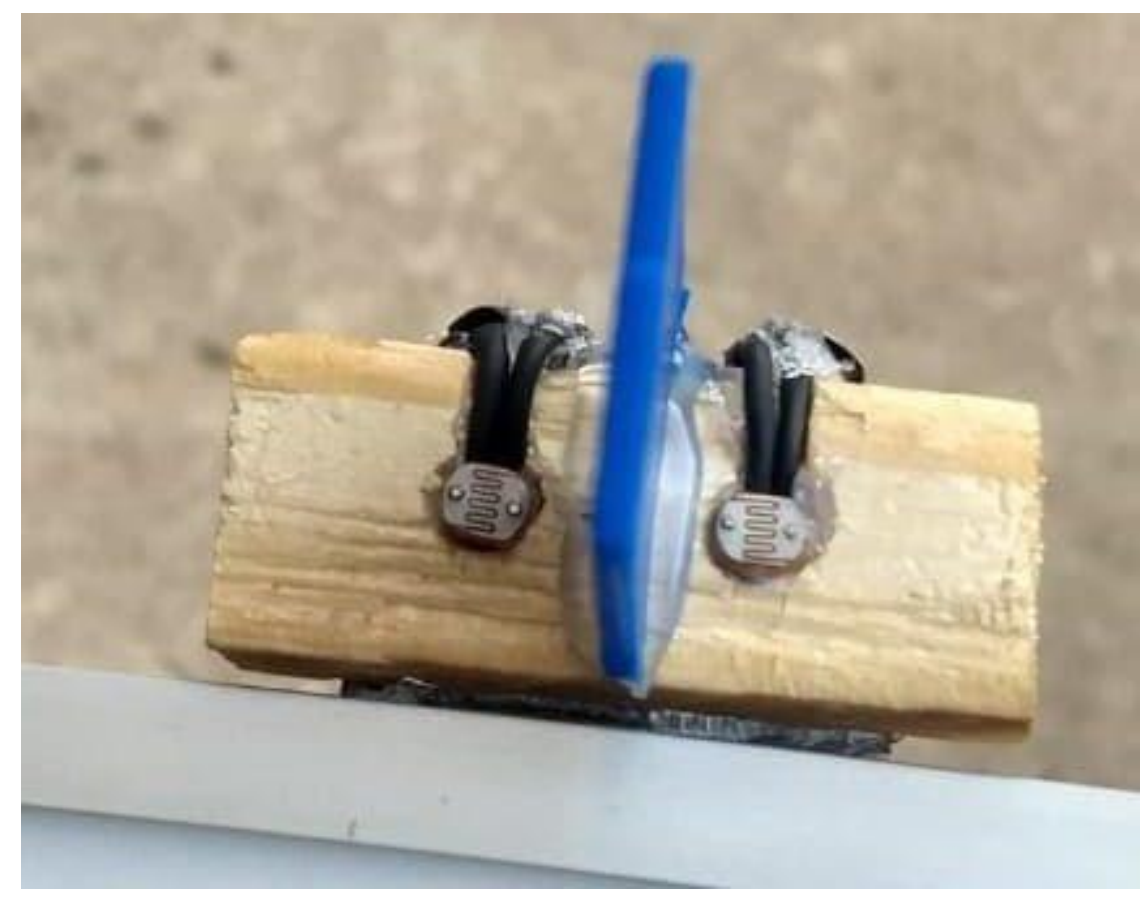

Fonte: Os autores, 2019.

Optou-se por realizar a leitura por 2 LDR's, pois o rastreador solar foi montado em um único eixo, diferente de Morón e outros (2017), onde foram instalados 4 LDR's e tiveram seu rastreador em 2 eixos.

Como descrito durante os resultados deste presente artigo, viu-se necessário a instalação de cargas. Foi escolhido utilizar duas lâmpadas de $21 \mathrm{~W}$, conforme Figura 13. 


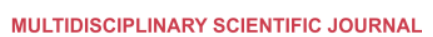

Figura 13 - Lâmpadas de 21W instaladas.

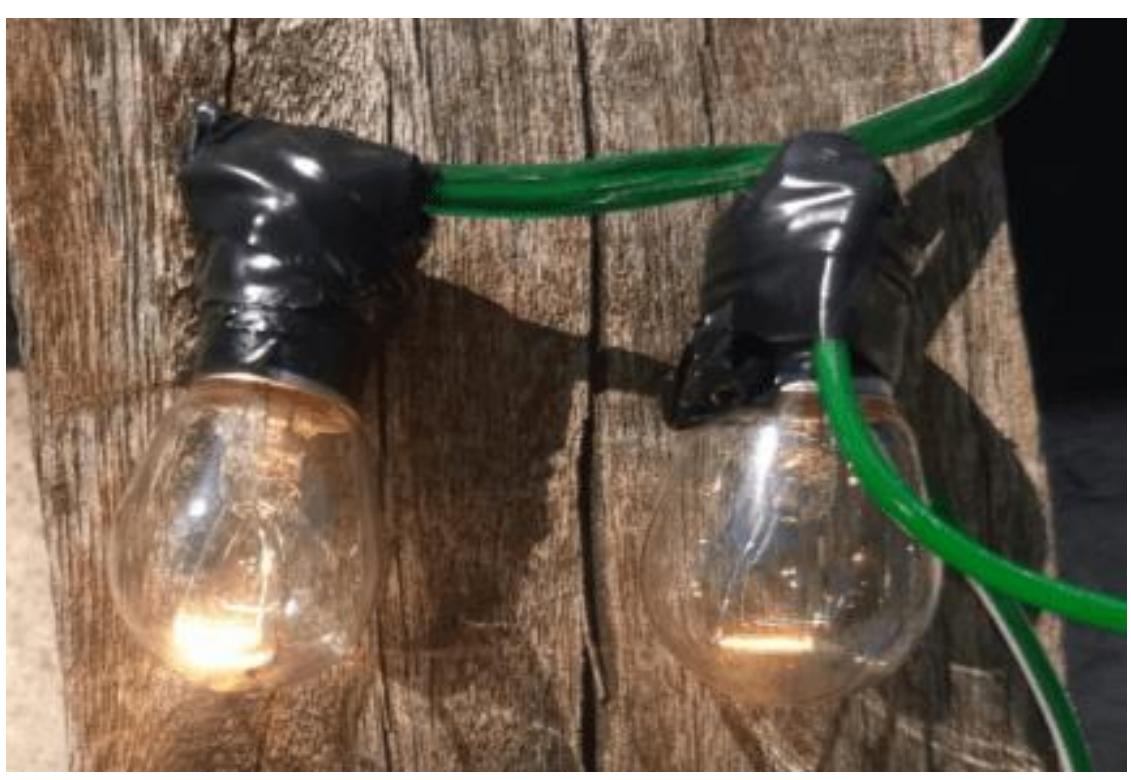

Fonte: Os autores, 2019.

Para suprir a necessidade de energia durante o funcionamento de todo o processo, a fonte de alimentação $12 \mathrm{~V}$ mostrada na Figura14, alimenta tanto o motor quanto o Arduino.

Figura 14 - Fonte 12V.

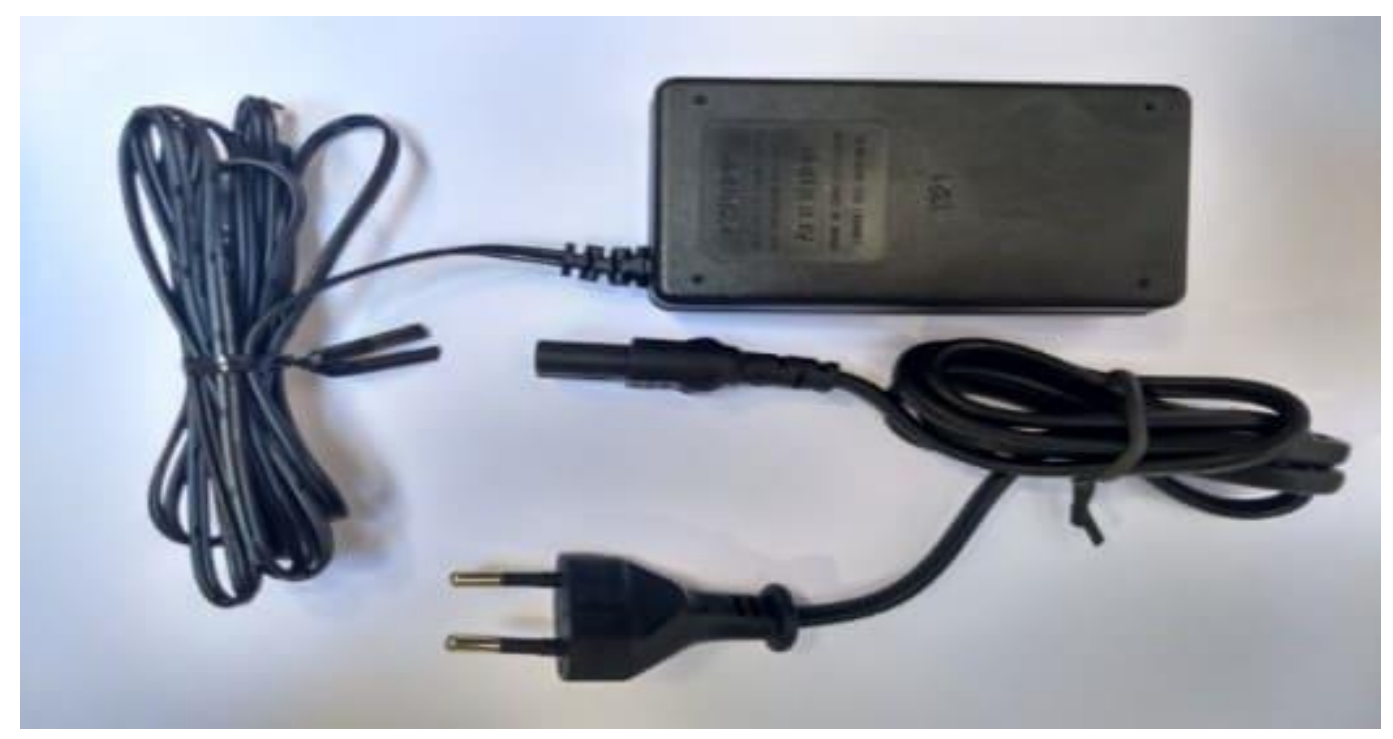

Fonte: Os autores, 2019. 
O rastreador solar escolhido para montagem foi do tipo rastreador em um eixo polar, em que o módulo é montado em uma inclinação fixa e o giro se ajusta no sentido leste - oeste para que a superfície da placa se mantenha corrigindo para estar sempre perpendicular aos raios solares.

O fluxograma do projeto, mostrado na Figura 15, destacou quais são as entradas e saídas do Arduino e toda a interação entre os componentes do circuito.

Figura 15 - Fluxograma do projeto.

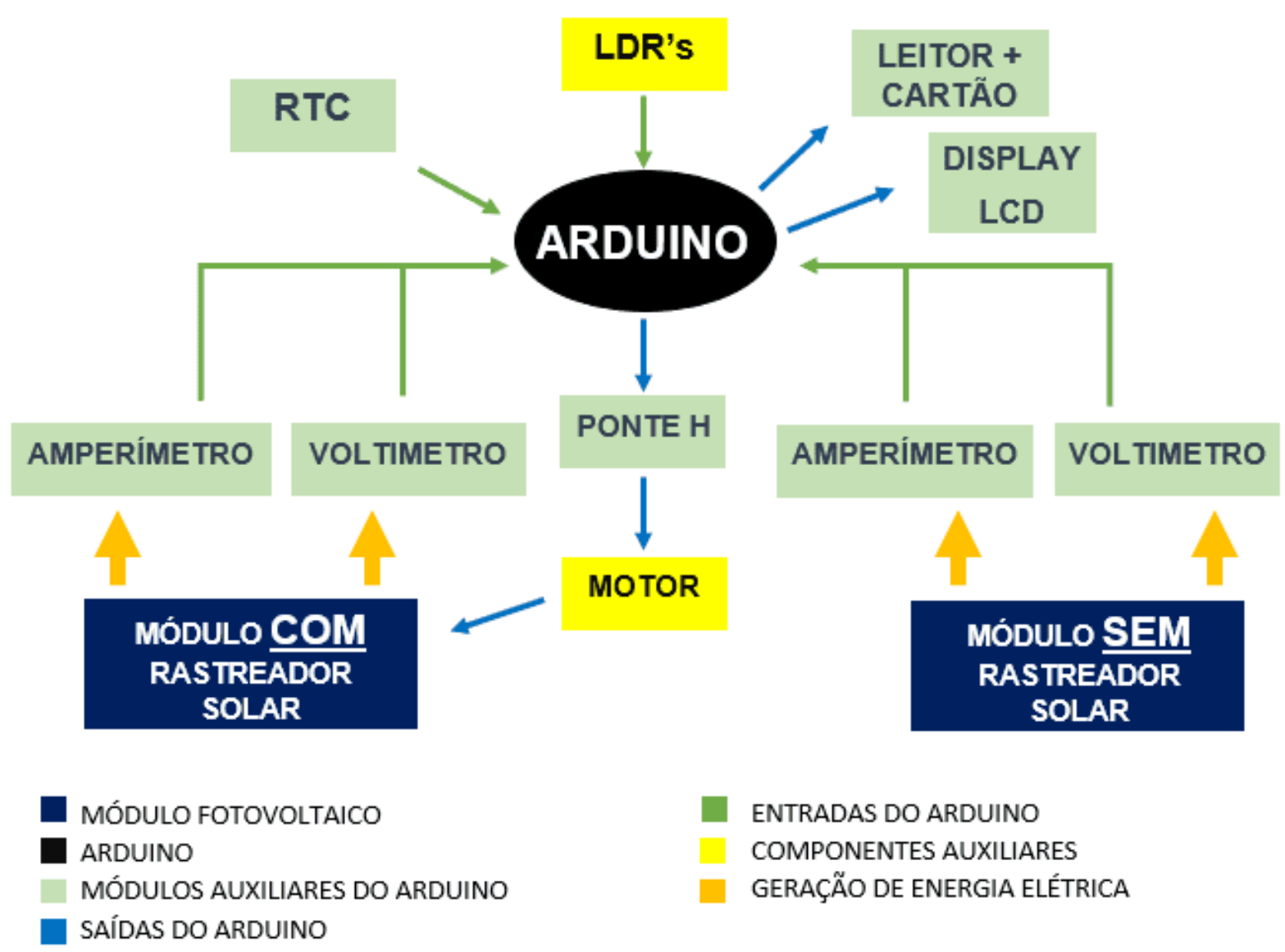

Fonte: Os autores, 2019.

A estrutura mecânica do rastreador solar é demonstrada na Figura16. 
Figura 16 - Estrutura do rastreador montada.
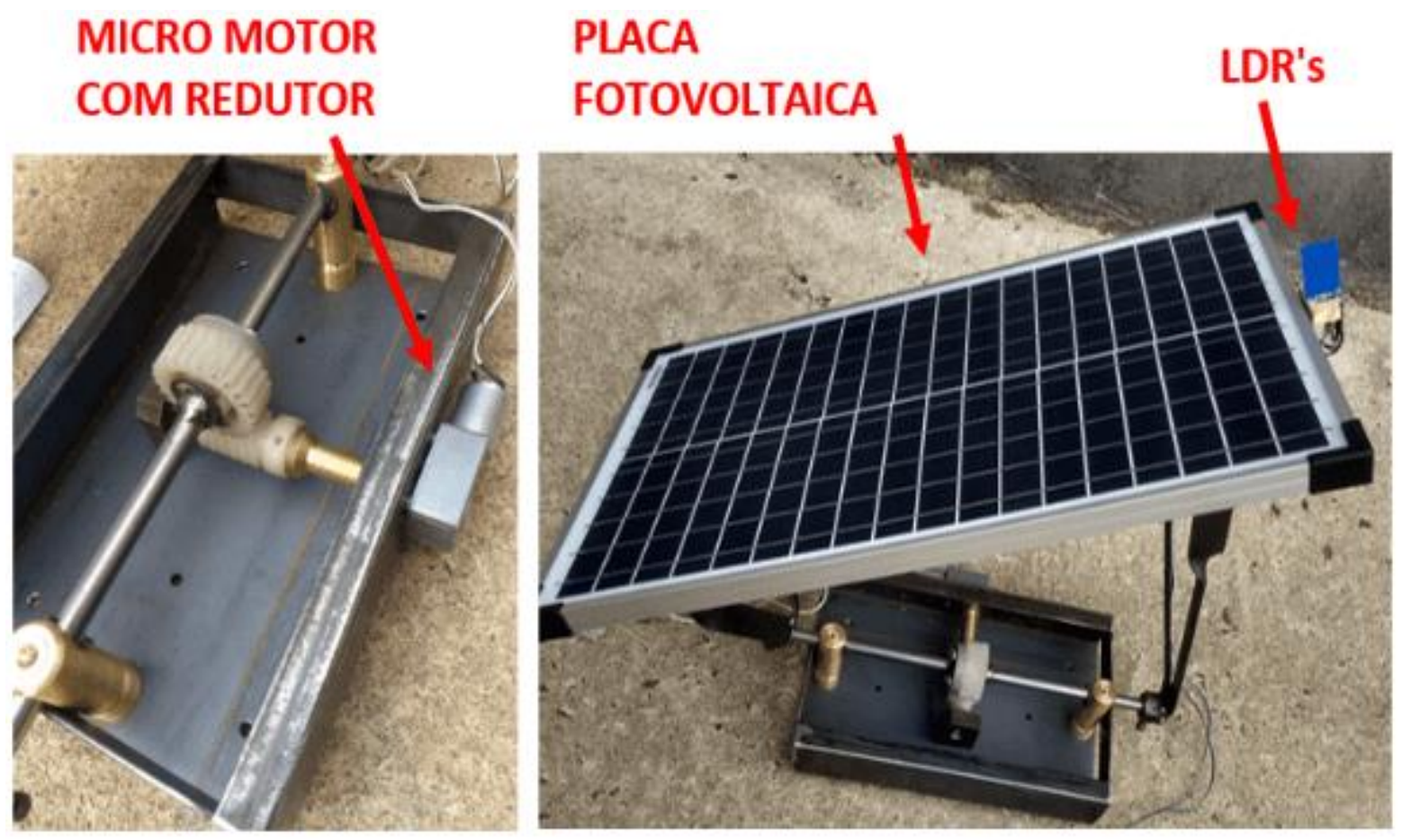

Fonte: Os autores, 2019.

A metodologia adotada para comparação dos sistemas foi a mesma que Restrepo, Castillo e Vera (2016), e se deu em coletar as leituras da medição da tensão de circuito aberto (VOC) e a corrente de curto circuito (ISC), tendo vária medições por minuto de ambos painéis, o fixo e o painel que está instalado o rastreador solar. A inclinação dos dois foi de aproximadamente $20^{\circ}$. Após coletar os dados durante o dia todo, foi retirado o cartão de memória do sistema e importado os dados para a análise. Para calcular a potência dos módulos fotovoltaicos foi calculado por meio da equação 1 .

$$
P=\text { VOC * ISC }
$$

Toda a projeção do circuito elétrico entre os componentes do protótipo é exibida na Figura 17. 
Figura 17 - Conexões elétricas do circuito.

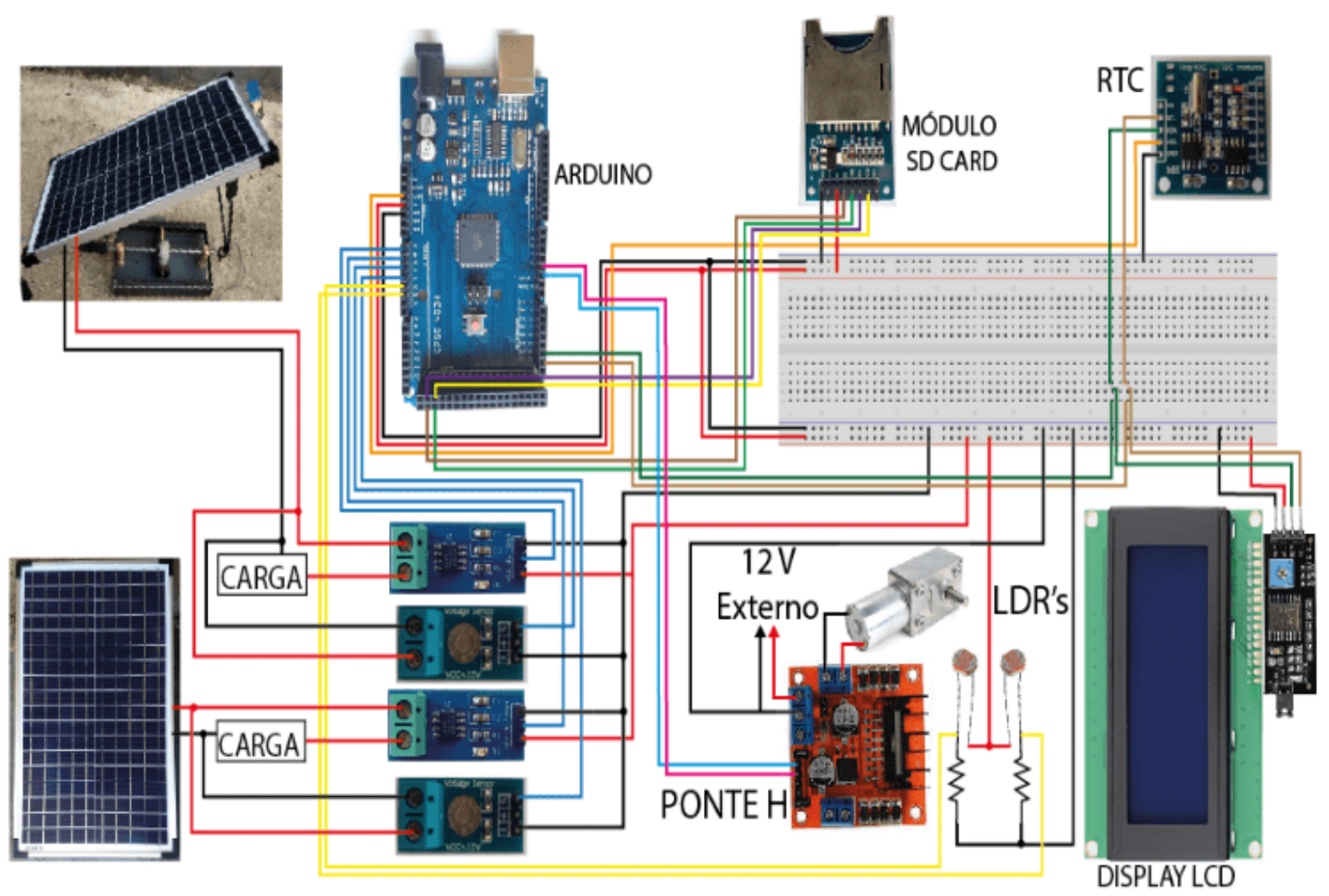

Fonte: Os autores, 2019.

A Figura 18 demonstra como ficou a distribuição e montagem dos componentes que realizaram o controle, funcionamento e medições dos sistemas. 
Figura 18 - Distribuição dos componentes.

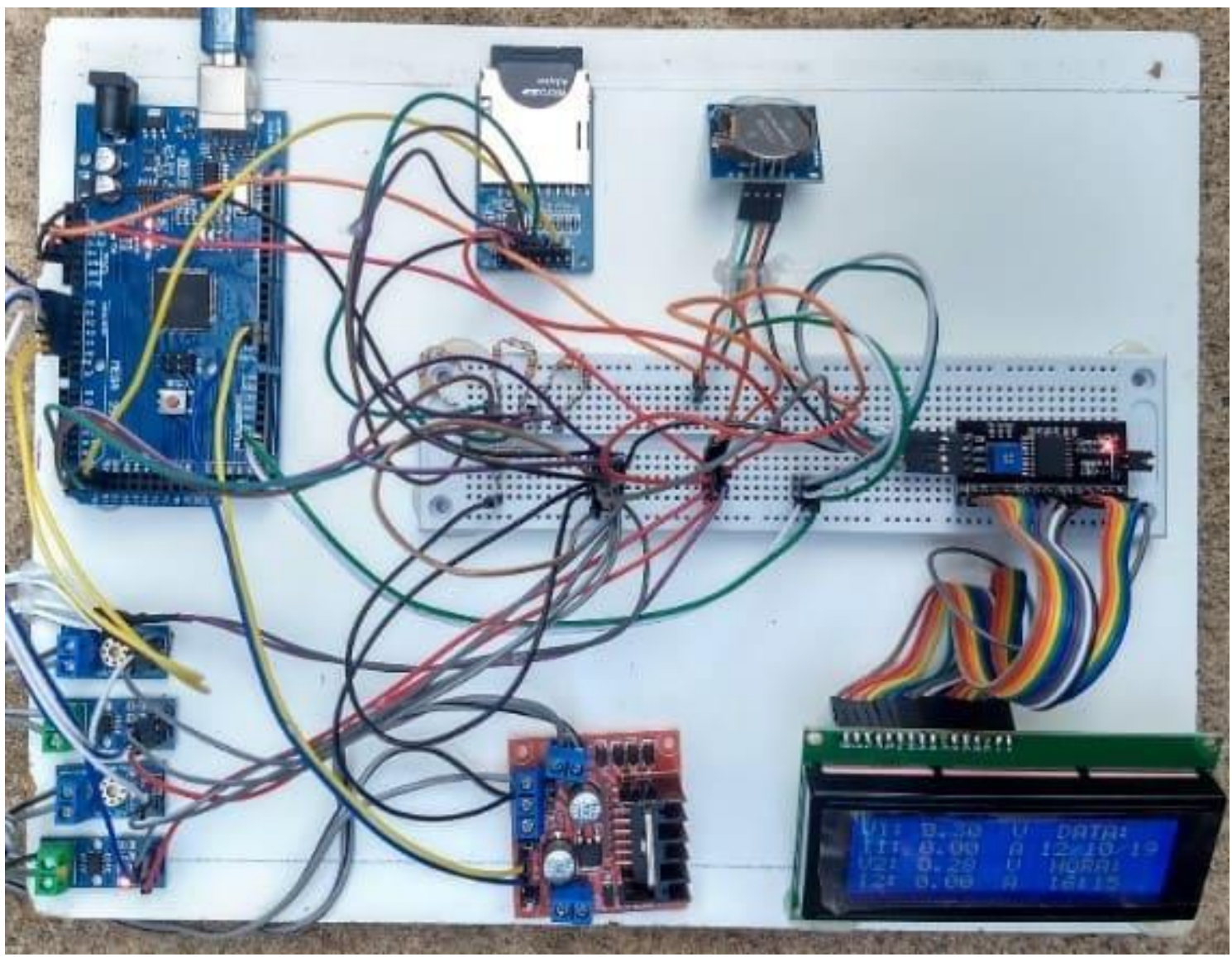

Fonte: Os autores, 2019

\section{RESULTADOS}

O primeiro ajuste feito no sistema, foi nos sensores LDR, onde a sensibilidade, que foi determinada pela diferença de leitura dos dois sensores, não estava bem ajustada e assim o Arduino não executava o acionamento do controle do motor. Após o ajuste na sensibilidade dos LDR's, apresentado na Figura 19, o sistema do rastreador funcionou perfeitamente, seguindo a posição do sol sempre que houvesse a diferença entre os dois LDR's. 
Figura 19 - Ajuste de sensibilidade dos LDR's.

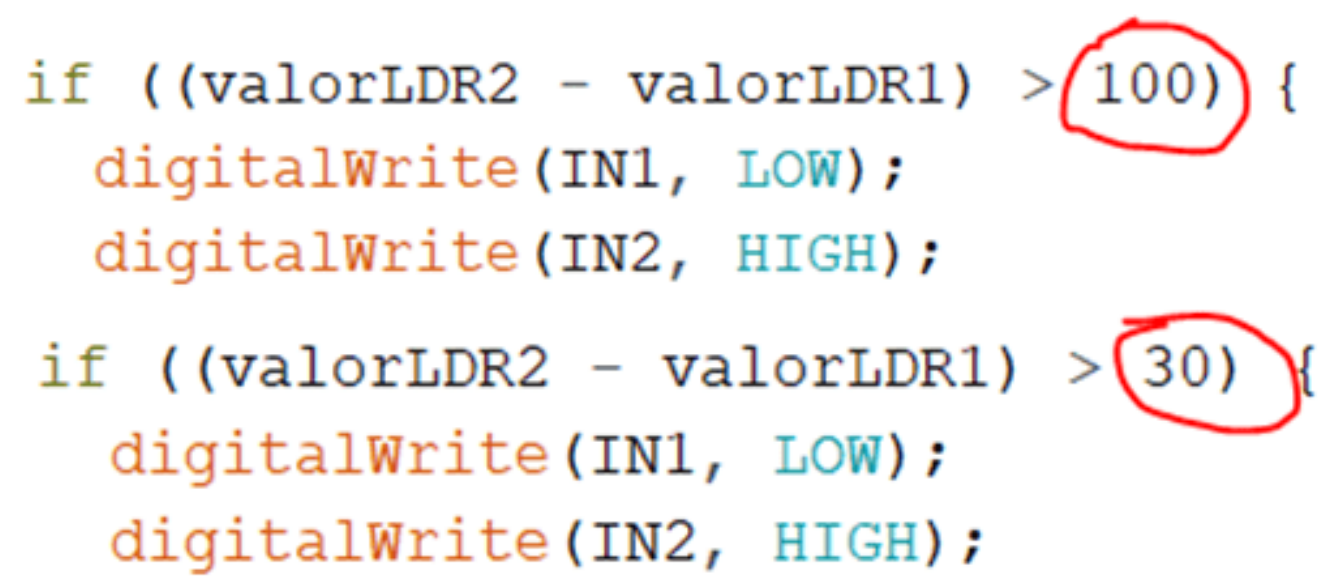

Fonte: Os autores, 2019.

Para medir a geração média das placas fotovoltaicas, foi feito a média de geração ao longo do dia e multiplicado pela quantidade de horas em que o sistema ficou em funcionamento.

Os testes do rastreador solar foram realizados sobre o telhado de uma residência. $O$ ângulo de inclinação adotado para ambas as placas solares foi de aproximadamente $20^{\circ}$. Os testes foram realizados durante o período da manhã até o fim da tarde, além de terem sido feitos testes em dia ensolarado e em dia nublado. A montagem para os testes pode ser observada na Figura 20. 
Figura 20 - Testes do rastreador solar.

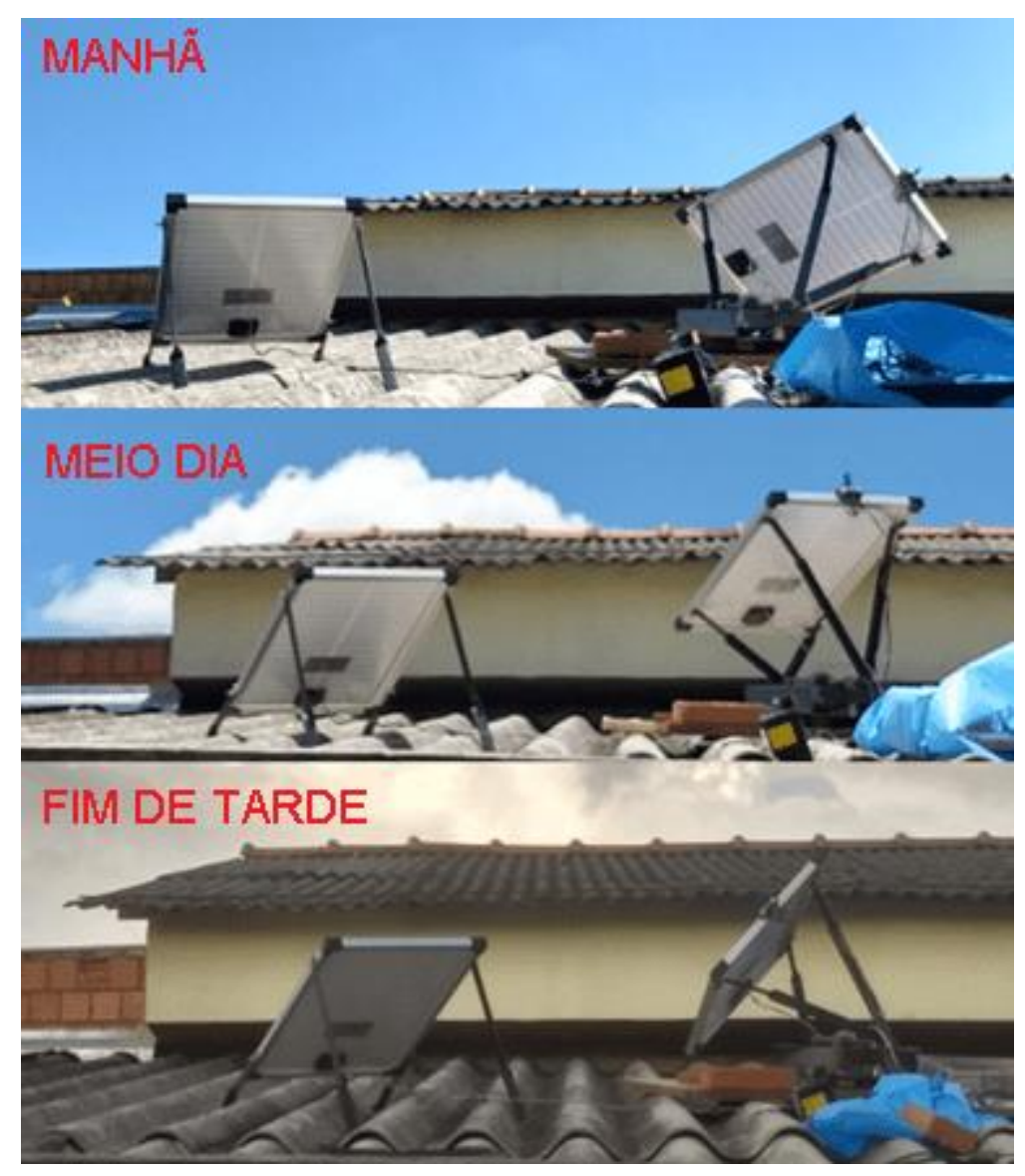

Fonte: Os autores, 2019.

A comparação de tensão VOC gerada nas duas placas, demonstrada na Figura 21, foi o primeiro resultado analisado. Ficou nítido que não houve uma diferença considerável na tensão VOC entre as duas placas. A Tabela 1, mostra os valores médios de geração e a melhoria, o ganho de tensão que foi medido e calculado. 
Figura 21 - Gráfico comparação de Tensão VOC (V) em função do tempo.

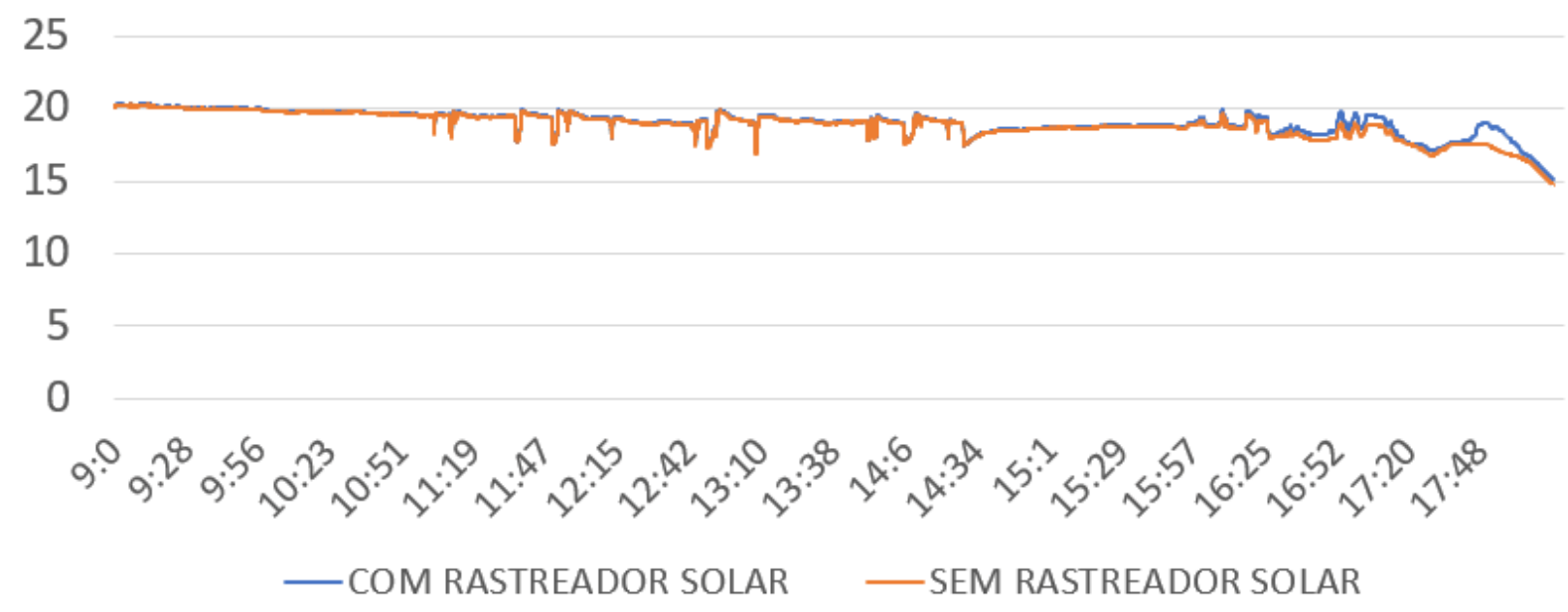

Fonte: Os autores, 2019.

Tabela 1 - Comparação de Tensão VOC.

\begin{tabular}{ccc}
\hline Medição & Painel com rastreador & Painel sem rastreador \\
\hline VOC Média ( v) & 19,022 & 18,862 \\
Ganho de tensão (\%) & 0,85 & ----- \\
\hline
\end{tabular}

Fonte: Os autores, 2019.

A medição de corrente ISC, foi feita no outro dia, onde na Figura 22, evidencia a diferença entre os sistemas. Porém ao realizar uma análise dos dados, ficou constatado que se tratou de um erro no programa, onde não se fez de forma individual a calibração dos sensores de corrente.

Vale ressaltar que mesmo os sensores ACS712 serem sensores idênticos, foi necessário calibrar os sensores individualmente pois eles podem ter uma pequena diferença de fabricação, onde com a calibração específica de cada um, tem esse possível problema minimizado. 
Mesmo com a falta da calibração de um dos dois sensores de corrente, foi evidenciado que ambos seguiram o mesmo padrão de oscilação, apresentado na Figura 22, alterando somente a amplitude das variações de leitura.

Figura 22 - Gráfico comparação de Corrente ISC (A) em função do tempo.

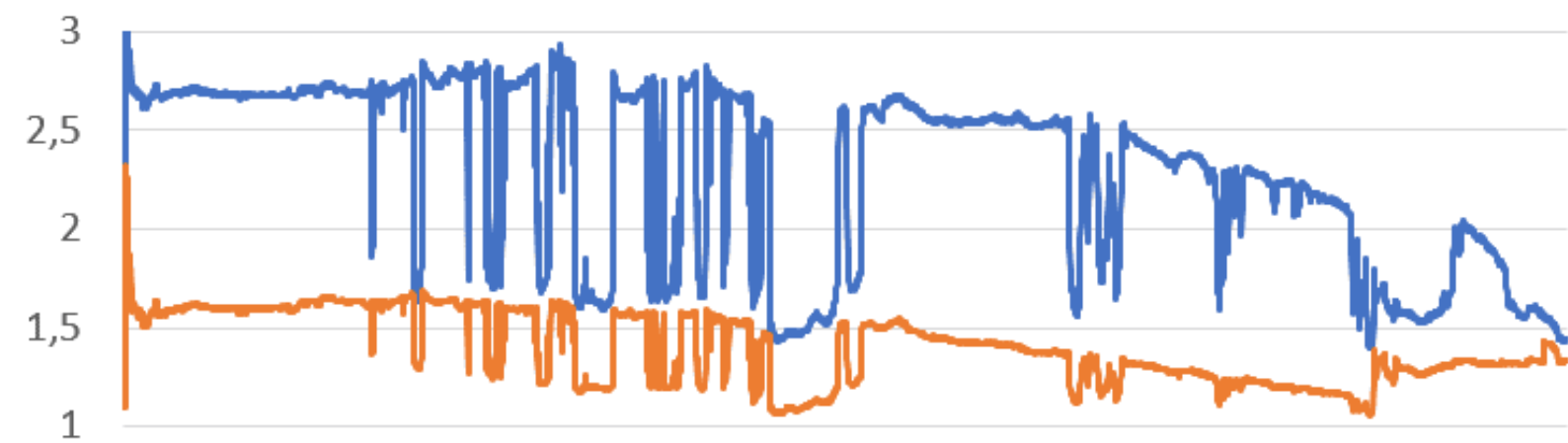

0,5

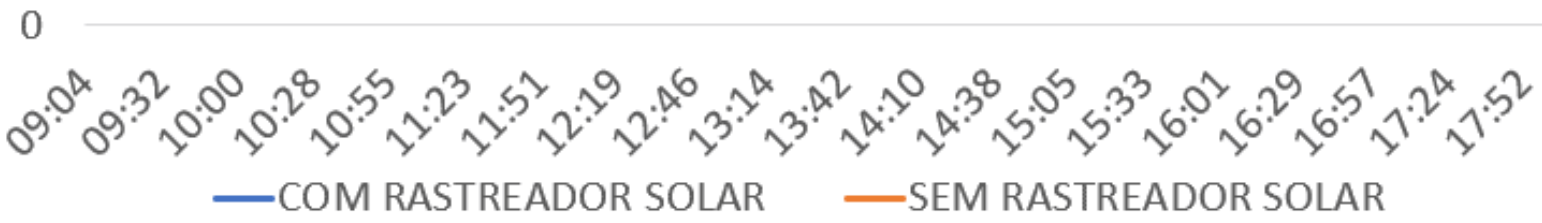

Fonte: Os autores, 2019.

Após ajustes da sensibilidade dos sensores de corrente, como mostrado na Figura 23, foi dado continuidade nos testes.

Figura 23 - Ajuste de sensibilidade dos sensores ACS712.

float sensibilidade padrão $=66 ; / / \mathrm{mV} / \mathrm{A}$

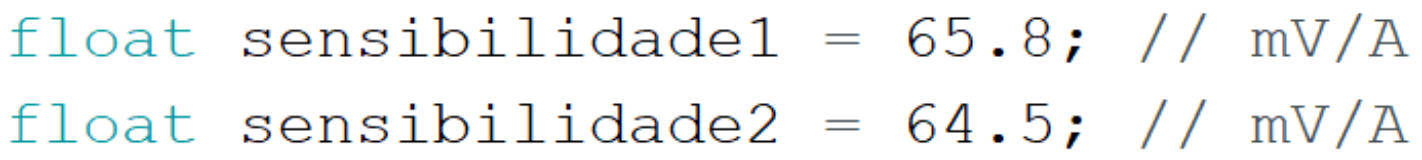

Fonte: Os autores, 2019. 
Tomando por base que as leituras de VOC e ISC, não apresentaram ganho entre o painel com rastreador e o painel sem rastreador solar, foi acrescentado uma carga em cada um dos sistemas, cargas idênticas. A intenção foi verificar como seria a medição da potência gerada das placas quando elas tivessem que alimentar cargas resistivas.

Com as cargas adicionadas, as medições de tensão e corrente puderam ser feitas de forma simultânea, assim executando o cálculo da potência que foi gerada.

Após analisar a Figura 24, onde mostra o gráfico de comparação da potência das duas placas com suas respectivas cargas conectadas. As medições foram feitas em um dia com bastante nuvens, por isso ocorreram constantes variações. Verificamos que entre os horários de 13:30h e 14:38h, não percebemos melhora alguma entre os dois sistemas e isso se deu pelo fato que nesse horário o Sol ainda estava em um ângulo onde se incidia de forma praticamente igual os raios solares sobre as placas. Após o Sol continuar sua trajetória, se deslocando ainda mais conforme o tempo se passava, percebe-se que começou a haver uma separação nas linhas do gráfico, o que aconteceu por volta de 16:00h. Depois desse horário foi onde se destacou o projeto do rastreador solar. $O$ rastreador por ter inclinado a placa ao longo do dia, continuou deixando-a perpendicular aos raios solares.

Figura 24 - Gráfico de comparação de Potência (W) em função do tempo em dia nublado.

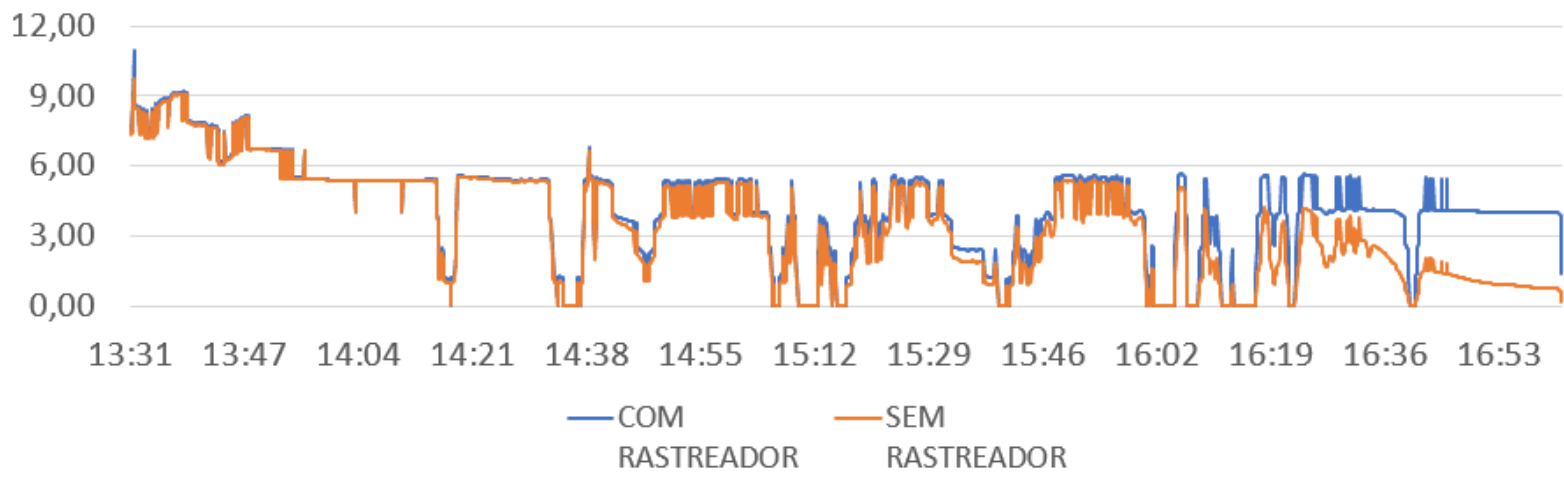

Fonte: Os autores, 2019. 
Ao fim do dia ficou evidente que houve uma grande variação da potência entre os dois sistemas, conforme detalhado na Figura 25.

Figura 25 - Detalhamento gráfico de comparação de Potência (W) em função do tempo em dia nublado após as 16:00h.

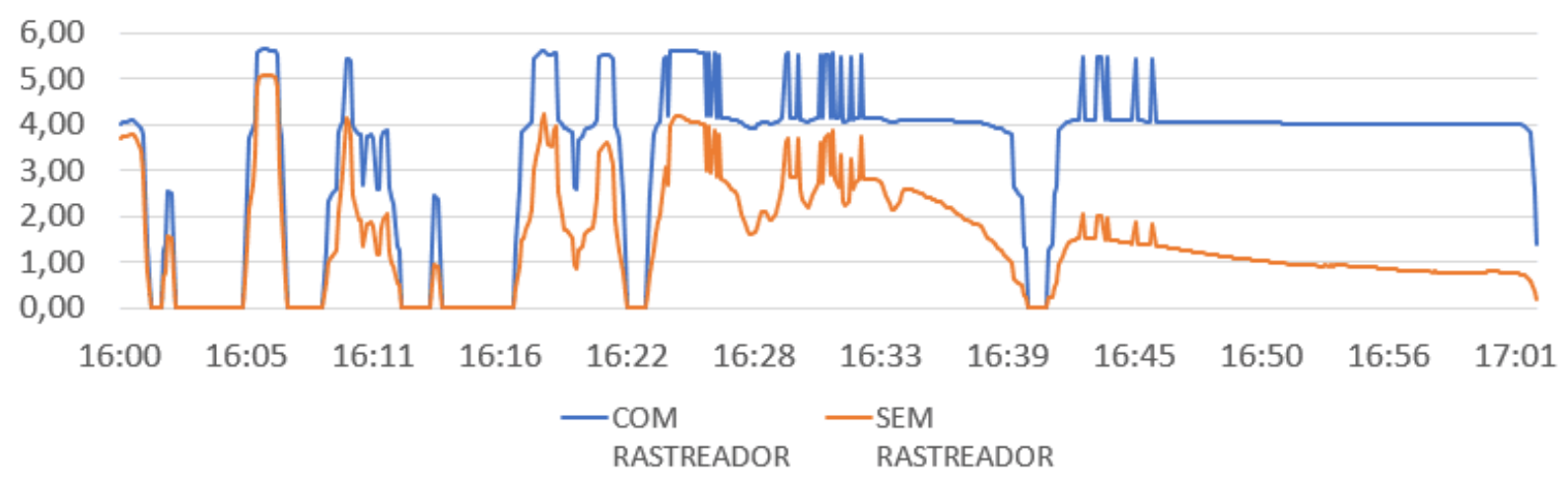

Fonte: Os autores, 2019.

A Tabela 2, destaca os valores de potência das duas placas e o rendimento que 0 rastreador solar trouxe para o sistema em dia nublado.

Tabela 2 - Comparação de Potência e rendimento dos sistemas em dia nublado.

\begin{tabular}{cccc}
\hline Medição & Painel com rastreador & Painel sem rastreador \\
\hline Potência Média & (w) & 4,13 & 3,46 \\
Horas de medição & 3,50 & 3,50 \\
Potência total (Pméd * horas) & (w) & 14,46 & 12,12 \\
Ganho de Potência (\%) & 19,29 & ----- \\
\hline
\end{tabular}

Fonte: Os autores, 2019.

A Figura 26, apresentada abaixo, evidencia uma nova medição realizada. Neste gráfico verificamos uma diferença da Figura 24, pois o dia em que foi realizado esta nova medição foi um dia ensolarado e com menos nuvens. O padrão que se repete é onde os valores medidos se assemelham muito desde o início das medições, até por volta das 16:00h novamente. 
Figura 26 - Gráfico de comparação de Potência (W) em função do tempo em dia ensolarado.

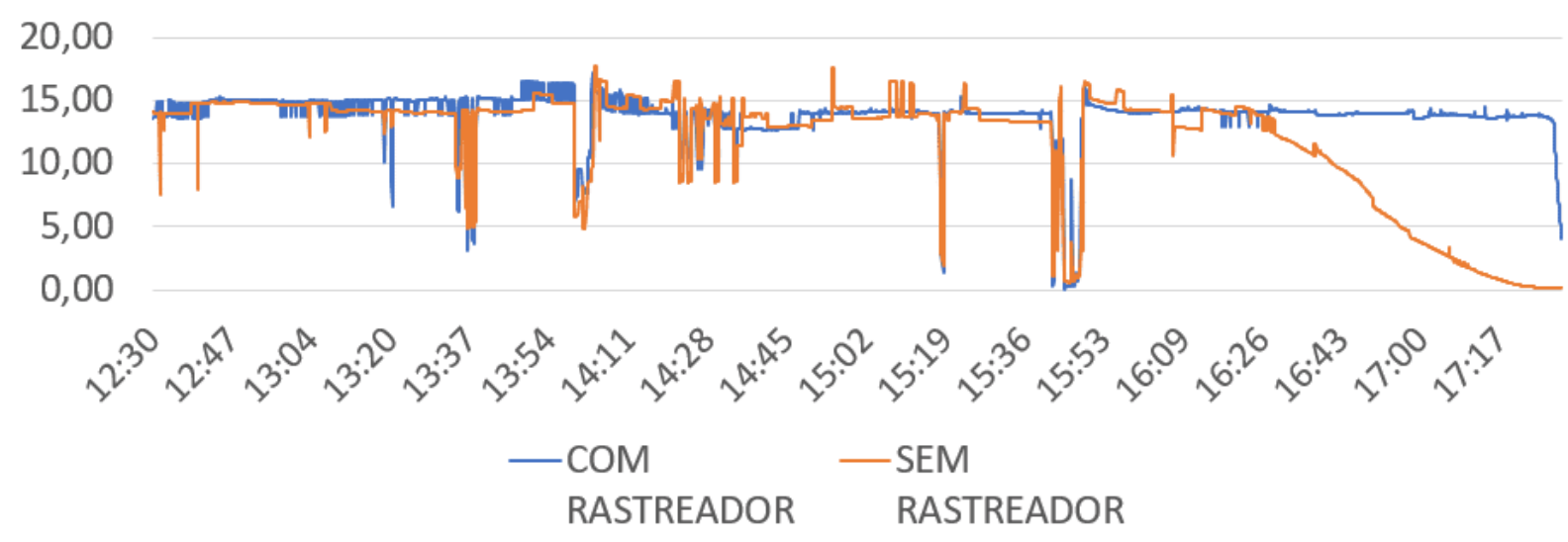

Fonte: Os autores, 2019.

A Figura 27 apresenta detalhamento do gráfico com medições em dia ensolarado, após as 16:00h, onde se constatou a grande distinção nos valores mensurados.

Figura 27 - Detalhamento do gráfico de comparação de Potência (W) em função do tempo em dia ensolarado após às 16:00h.

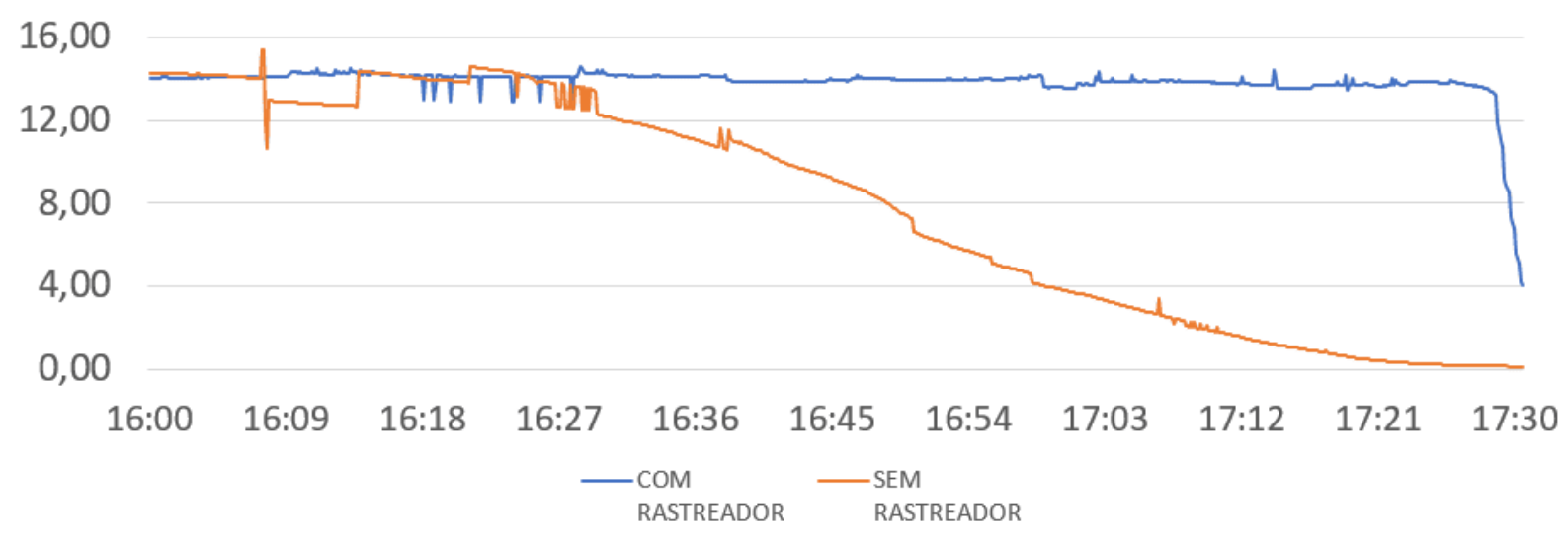

Fonte: Os autores, 2019.

A Tabela 3, apresenta os valores de potência da segunda medição, das duas placas e o rendimento que o rastreador solar trouxe para o sistema em um dia ensolarado. 
Tabela 3 - Comparação de Potência e rendimento dos sistemas em dia ensolarado.

\begin{tabular}{|c|c|c|}
\hline Medição & Painel com rastreador & Painel sem rastreado \\
\hline Potência Média (w) & 13,83 & 11,86 \\
\hline Horas de medição & 5,00 & 5,00 \\
\hline Potência total (Pméd * horas) (w) & 69,13 & 59,28 \\
\hline Ganho de Potência (\%) & 16,62 & $\ldots$ \\
\hline
\end{tabular}

Fonte: Os autores, 2019.

\section{CONCLUSÃo}

O presente artigo teve o objetivo de desenvolver um sistema de rastreamento solar e aplicá-lo à uma placa fotovoltaica. O modelo escolhido foi de rastreador em um único eixo. O protótipo foi desenvolvido e testado, após os testes foi comprovado o funcionamento do rastreador.

A análise de eficiência entre o sistema fixo e o sistema com rastreador foi feito a partir das medições de tensão e corrente da placa conectada à uma carga, já que sem o uso de uma carga não foi constatado melhora alguma de eficiência do sistema.

Com a carga conectada o resultado foi de uma melhora entre $16 \%$ e $19 \%$ com o uso do rastreador solar, com os testes realizados em dia ensolarado e nublado, respectivamente.

Sugestões de trabalhos futuros, são a de construir um rastreador solar de dois eixos e verificar a eficiência desse sistema. Outra sugestão é analisar o consumo do rastreador solar e realizar a relação custo $\mathrm{x}$ benefício e ainda a implementação de um sensor para indicar a inclinação da placa fotovoltaica. Além de realizar otimizações no código de execução do Arduino.

\section{REFERÊNCIAS}

ATMEL, Atmel ATmega640/V-1280/V-1281/V-2560/V-2561/V. EUA: Atmel, 2014. Disponível em < http://ww1.microchip.com/downloads/en/DeviceDoc/Atmel-2549-8- 
bit-AVR-Microcontroller-ATmega640-1280-1281-2560-2561_datasheet.pdf >. Acesso em: 25 abril. 2019.

CABRAL, Isabelle de Souza; TORRES, Adriana Cazelgrandi; SENNA, Pedro Rocha. Energia solar - Análise comparativa entre Brasil e Alemanha. In: Congresso Brasileiro de Gestão Ambiental, 4., 2013, Salvador. Anais eletrônico. Salvador: CONGEA, 2013. Disponível em: <http://www.ibeas.org.br/congresso/Trabalhos2013/X-009.pdf >. Acesso em: 15 ago. 2019.

CRESESB, Potencial solar. Rio de Janeiro, RJ: CRESESB/ CEPEL, 2018. Disponível em: <http://www.cresesb.cepel.br/index.php?section=sundata>. Acesso em: 07 mar. 2019.

MAGARREIRO, Clarisse; FREITAS, Sara; BRITO, Miguel Centeno. Radiação e energia solar. Gazeta de Física. Lisboa, v. 39, n 1/2, p 57- 59, jul. 2016.

MORÓN, Carlos; e outros. New prototype of photovoltaic solar tracker based on Arduino. MDPI. Basel - Switzerland, v.10, 1298, ago. 2017. Disponível em: <https://www.mdpi.com/1996-1073/10/9/1298/pdf> Acesso em: 10 ago. 2019.

PEREIRA NETO, Édio; SILVA, Gláucio José Pereira da. Protótipo de um rastreador solar ativo de um eixo. 2010. 94 f. Instituto Federal de Educação, Ciência e Tecnologia Fluminense, 2010.

PINHO, João Tavares; GALDINO, Marco Antonio. (Org.). Manual de engenharia para sistemas fotovoltaicos. Rio de Janeiro: CEPEL - CRESESB, 2014. 529p. Disponível em

http://www.cresesb.cepel.br/publicacoes/download/Manual_de_Engenharia_FV_201 4.pdf >. Acesso em: Acesso em: 25 abril. 2019.

PORTAL SOLAR, Tudo sobre a eficiência do painel solar. São Paulo, SP: Portal Solar, 2018. Disponível em <https://www.portalsolar.com.br/tudo-sobre-a-eficiencia-dopainel-solar.html >. Acesso em: 20 mar. 2019. 
RESTREPO, Cristian Manuel Agudelo; CASTILLO, Oscar Daniel Díaz; VERA, Yimi Edisson García. Evaluación de un prototipo de seguimiento solar fotovoltaico en regiones tropicales. Redes de Ingeniería. Bogotá, v.07, pp. 105-111, jun. 2016. Disponível em:

https://revistas.udistrital.edu.co/index.php/REDES/article/view/10055/11681> Acesso em: 5 ago. 2019.

Enviado: Maio, 2020.

Aprovado: Agosto, 2020. 